\title{
Social Protection in Zambia - Whose Politics?
}

\author{
Esther Schüring and Julie Lawson-McDowall*
}

\begin{abstract}
Attempts have been made to explain why social protection systems seem least likely to become established where they are most needed. Often, however, these attempts have not captured the rather complex politics in the countries in question. Analyses have turned the Minister of Finance into the sole representative of political will, have equated low budgetary allocations with a politically unattractive programme design and have ignored the long and erratic histories of social protection in the Western world. The appropriate roles for donors and civil societies in such political economies remain equally unclear. On the basis of other 'drivers of change' studies, this article takes a closer look at the political dynamics behind social protection in Zambia. It examines whether the observed or deduced stagnation in social protection is due to stakeholders in Zambia rejecting policy recommendations, the inappropriate nature of these recommendations or a premature assessment of progress made.
\end{abstract}

\section{Introduction}

Consideration of the socioeconomic ripple effects of the HIV/AIDS pandemic, the impact of the 'triple F' (food, fuel and finance) crisis, the failure of economic growth to impact broadly on poverty reduction and the increasing pressure to show progress towards the Millennium Development Goals (MDGs), would seem to make social protection the policy instrument of choice in low-income countries. Yet, in some of the countries with the worst chronic poverty, scepticism regarding social protection appears to prevail, despite exposure visits to Latin America, tailor-made training courses, much generation and communication of evidence regarding the positive impacts of social protection initiatives and increasing donor commitments.

Zambia, in particular, has been criticised for a lack of government commitment to social protection generally, but especially to social cash transfers (SCT). SCT started in Zambia in Kalomo district as a donor-funded initiative in 2003, and was later extended to five districts. This pilot project aimed to generate evidence and offer government and the Ministry responsible - Community Development and Social Services (MCDSS) - the necessary information and skills to demonstrate the value of social protection for citizens who have limited or no productive capacity. The SCT was proposed alongside other social protection interventions, as illustrated by the first national Social Protection Strategy in 2005.

While small victories have been won, such as the creation of a budget line for SCT, maintaining a degree of funding for other interventions, deploying more staff and winning over allies (some Members of Parliament and a few previously opposed Ministers), progress overall has been slow. For example, it has taken the Ministry almost three years to scale-up the SCT beyond the five initial pilot districts, and development partners still foot most of the bill. Piloting and experimentation continue (SCT are now targeted to the 'incapacitated' in some districts, to the elderly in others and to children in the most recent districts) with, however, little political commitment to take the SCT forwardin whatever form. Increased funding for other important social protection interventions has been equally elusive.

Academics and development practitioners have sought answers as to why pro-poor social protection has not taken stronger root in Zambia, starting as early as 2005 with a 'drivers 
of change' study (Barrientos et al. 2005); studies featuring Zambia in 2008 (Lindström 2008); in 2009 (Habasonda 2009; McCord 2009) and in 2010 (Devereux et al. 2010; Devereux and White 2010; Niño-Zarazúa et al. 2010). Is the stagnation that we currently observe because stakeholders in Zambia resisted policy recommendations and, if so, why? Is it because recommendations were wrong-headed or inadequate, or is it a mistake to conclude that we see no progress in Zambia?

\section{The politics behind social protection in Zambia}

Donors supporting social protection in Zambia endeavoured to analyse political processes to see how social protection might better fit the local political agenda. A key document was the Drivers of Change for Social Protection analysis in 2005 (Barrientos et al. 2005). That report identified several barriers to social protection interventions: a tendency towards a 'massification of poverty', the complex and impenetrable language employed and a MCDSS with low human, organisational and financial capacity. It argued that donors must push for a stronger focus on the poor and vulnerable and encouraged them to make use of existing institutions, engage with powerful social and economic sector ministries and the Minister and Ministry of Finance, to ally with civil society and research institutions and to prioritise monitoring and evaluation.

Here, in response to the identification of these weaknesses and the recommendations made, we examine the nature of the social protection policy process in Zambia and trace why a political contract between government and its citizens for social protection has not been established. Deconstructing possible explanatory factors, we look at institutional features, the overall discourse on poverty, the existing knowledge base for policymaking, different drivers of change and implications for the design and implementation of social protection programmes.

\subsection{Institutional features}

Putting social protection into the broader context

Recent social protection analyses in Zambia may have underplayed the broader policy and programming context while shining rather too harsh a spotlight on social protection. We argue that, in the context of Zambia's long-term economic decline from middle-income to low- income status, and the resulting (and concomitant) structural adjustment processes, a policy and funding void emerged around responses to poverty which persists today. Poverty alleviation was subsumed under growth while government investment across the board has been shaped by the dynamics of the shadow political economy, dominated by a patron-client/ patrimonial/prebendalist rationale. Poverty and vulnerability responses by government have, consequently, been piecemeal, underfunded and projectised, and often delivered through nongovernment channels.

The real national agenda and the magnitude of challenges ahead are revealed by the budget allocation for poverty alleviation and social protection measures. In 2010, the MCDSS budget ceiling was fixed at 0.5 per cent of total government revenue (about US\$15.5 million). The allocation for Food Security Packs, a national programme to support poor small-scale farmers, represented just 13 per cent of this small budget, while that for the in-kind transfers provided by the Public Welfare Assistance Scheme (PWAS) - also supposed to be a national programme - amounted to 7 per cent of the entire MCDSS budget (Ministry of Finance and National Planning 2010). To fund a national SCT scheme targeting 10 per cent of households (for calculations see ILO 2008), the present MCDSS budget would have to be doubled.

\section{Personalised decision-making}

Where there have been significant shifts in social protection policy, a careful examination reveals their highly personal and opportunistic nature. For example, until October 2005, rural health user fees, introduced in the 1990s, seemed a fixture and the Ministry of Health was firmly prouser fees. The reform trigger was an idiosyncratic combination of factors and events: the Minister, a visionary champion able to manipulate free political space due to her non-membership of the ruling party, motivated by a personal encounter with poverty, teamed up with a donor that was able to mobilise support quickly. Similarly, the former Minister of the MCDSS managed in 2007 to mobilise rapidly a significant budget for streetchildren, partly to the detriment of the national in-kind transfer programme. A personal interest became a political priority for these particular actors, enabling them to change a political course of action. 


\section{Political spaces}

Unfortunately, then and now, unofficial policy space is often more important and more difficult to influence. Political economy analyses suggest that: 'Zambia has long been characterized by a disconnect between its formal institutional structure, and the informal "rules of the game", (Levy and Palale 2007: 10).

Since independence, important constituencies in Zambia, either ethnic, linguistic, regional or political elites or a mixture, have been balanced through access to patronage rents of one form or another. These 'mutual guarantees of economic and political support within social networks' inhibit the functioning of the 'mechanisms of performance-based accountability' (Posner and Simon 2002: 332) and do not provide easy entrypoints for outsiders to influence policy. The seismic political and economic shifts from the 1990s onwards - continuing economic decline as well as a split in the governing party and the almost total disintegration of the opposition party - did little to reduce the informal policy space.

The focus on rent creation and allocation for political management meant that unofficial political-economic imperatives were as important as official ones, but even less likely to be pro-poor. Both official pro-growth and unofficial pro-rent generation dynamics limit the space and the paths along which the poor might be able to make themselves heard, and thus complicate the inception of national social protection interventions.

\section{Accountability}

In Zambia today, political accountability remains limited. It is not clear to what extent politicians who fail to deliver are voted out of power. To whom must an MP deliver? Dependence on relations with the leaders of the party for the resources and opportunity to be elected means that constituents have much less influence than the formal structure suggests. A study examining factors of support for the 1991 and 1996 elections at sub-national level found 'non-economic factors such as urban-rural location and ethnic background to have been at least as important as economic factors in shaping voters' behaviour' (Posner and Simon 2002: 319). They also found evidence that along the familiar exit/voice/loyalty spectrum, exit - in terms of not voting/abstaining - was still, as under the single party system, regarded as a valid strategy. Evidence of a small shift away from prebendalist voting patterns by Posner and Simon (2002) is a sign that incumbents will increasingly be judged on their performance in office. This accountability bodes well for the future of social protection.

\section{Towards a social contract?}

The coexistence of official and unofficial policy spaces leaves the majority of the population excluded from policy influence. Yet, for a social contract to emerge, it has to be recognised by both sides and, to some extent, be enforceable.

Despite the fact that social protection is gradually being institutionalised and integrated into the Social Security Policy, the draft Social Welfare Policy, the National Development Plan and so on, nothing yet allows citizens to take the government to court, as in countries like South Africa. A key issue in Zambia's Constitution debates concerned whether access to education could be a right, let alone the progressive realisation of social and economic rights. The fact that the draft Constitutional Bill has included a 'right to social protection' is, however, extremely promising with respect to the longerterm future of social protection.

\subsection{Discourse and thinking on poverty Elites}

How is poverty understood by Zambians? A mixed picture emerges from political elites as well as the broader public. Earlier studies suggested that the elite (the wealthiest 3-5 per cent of the population) feared welfare traps and irreversible political commitments. Commentators have argued that elites prefer tools directed at the 'productive poor' (Barrientos et al. 2005; Hickey 2007). However, there is evidence that this view has shifted and we now find a more nuanced view within the Ministry of Finance (Lindström 2008; RuralNet 2008), a richer debate on social protection in Parliament (Zambian Parliament 2010) and, in policy terms, social protection, once a side chapter in the 5 th National Development Plan, is being considered as a right in the new Constitution.

\section{Public opinion}

What do 'ordinary Zambians' think about the incapacitated poor? We argue here that ordinary Zambians do care - as much as they can afford to and show this in their daily actions through taking 
in orphans or participation in faith-based care organisations. This is also confirmed by a small political attitude survey, ${ }^{2}$ exploring how Zambians understand 'the poor' and the acceptability of various responses to poverty (Schüring 2010).

Respondents, broadly speaking, accept that there are structural causes of poverty, simultaneously expect high levels of individual responsibility but accept that some people should be given noncontributory support. There is a strong feeling that the government has a primary responsibility for care of the poor. Only a tiny percentage, when asked to imagine themselves as policymakers, denied any form of support to the poor.

\subsection{Knowledge base - the right message to the right people? \\ Merging science with reality}

In Zambia, numerous studies have been commissioned on the impact of SCTs, their operational efficiency with regard to targeting, payments, incentives, conditionality and institutional arrangements and fiduciary risks. Much effort was given to ensuring the process was transparent and credible, data and studies were shared with a wider audience and areas for improvement were highlighted along with achievements. In short, an evidence base for Zambia has been constructed as recommended in the 'drivers of change' study (Barrientos et al. 2005).

Unfortunately, policymakers do not base decisions on evidence alone; this applies in particular to the 'true believers' (Pritchett 2002). The former Zambian Minister of Finance, a 'true believer' that cash transfers would either be captured or mis-spent, based his view on his personal experience as an agricultural credit officer and a few cash transfer recipients in his home district, rather than examining the broader and more positive evidence. This means that a randomised broad-scale experiment is unlikely to have provided a tipping-point. Evidence is a necessary but not sufficient condition for social protection in any country where personalities and other policy considerations dominate.

\section{Market social protection better?}

A key question in Zambia is whether stakeholders found the right channels of communication for social protection and whether, in particular, they failed to emphasise its potential to stimulate local economic growth. Finding the right language and evidence is crucial in addressing the concerns and fears of a Ministry of Finance. However, there is a real risk of claiming social protection as a silver bullet and/or not recognising the budgetary implications and difficult allocation decisions that governments face.

If SCT programmes are promoted primarily on their propensity to promote growth, they will be assessed against other productive programmes and will probably fail the test. This would take us back to growth with no protection for those least able to participate. Also, while the ILO (2008) has advocated that a minimum package of universally acceptable benefits is affordable, even a social protection budget around 1 per cent of GDP means a significant budget increase for countries like Zambia that mobilise only about 25 per cent of GDP as government revenues.

\subsection{Drivers of change - going the right way? Civil society needs to step up}

Civil society in Zambia is a diverse group of organisations, active in lobbying for the poor and vulnerable and delivering many vital services on the ground. Mass movement has arisen only at crucial moments in the democratic evolution. Otherwise, sporadic pressure has been exerted on the government and only by some organisations. In social protection, civil society has mainly played a consultative role, although the initiative of a civil society platform for social protection has gained some momentum of late.

Is it fair to suggest that civil society has failed to provide national leadership on social protection? A more sophisticated and dynamic understanding of the limitations of civil society in a country such as Zambia would suggest not. The shrinking of the middle class and absence of a pro-poor activist elite means Zambian NGOs are almost entirely dependent on funding from external sources. Givil society engagement is curtailed by lack of funds and activities are curtailed by donor strategies. The NGO Bill in 2009 further limited room for manoeuvre through introducing a government-dominated Registration Board that approves or denies the establishment or mandatory re-registration of NGOs (Vind-Andersen 2009).

The influence that civil society could and can bring to bear in Zambia is therefore highly constrained. 


\section{Donors taking too much of the initiative}

Have donors taken too much of the initiative in social protection? Our finding is to the contrary, that donors, overall, did not take sufficient initiative given the presence of a policy void that was damaging to the poor and vulnerable. This is not to argue that donors should attempt to impose their preoccupations on the policymaking process but they should certainly act to support local actors, institutions and processes that benefit the poor and vulnerable.

Donor initiatives in social protection in Zambia have followed more than one agenda, which might not have fostered consistency in policymaking and ministerial ownership. In their defence, however, it must be stated that development partners made extensive use of official policy space, particularly through the Technical Working Groups (TWG) that fed into the Sector Advisory Group (SAG). Without the support of donors, poverty and social protection would not have risen on the agenda of those who make decisions and MCDSS would not have the same capacity and clout as today.

\section{Appropriate institutions}

Academics and practitioners in social protection debate at length whether to work with existing or new institutions. Many advocate that a more powerful ministerial home would further the agenda and that working with weak Social Affairs ministries is self-defeating. There are some serious difficulties with this suggestion, however. To shift a social transfer programme from the ministry which holds a mandate presupposes an interest in the recipient for inter-sectoral adoption. In the Zambian context, this was a nonstarter. The Minister of Finance was one of very few Ministers of Finance absent from the regional Livingstone conference on social protection (hosted in Zambia!) in 2006 and he was reluctant in 2007 to sign an SCT grant agreement for which the MCDSS lobbied strongly. Furthermore, social protection interventions at a time when donors are preoccupied with alignment, harmonisation, division of labour and delivering results need to promote government systems and to support a broader Ministry of Social Affairs mandate, rather than elevate a single intervention.

\section{The government?}

Most critics of the failure of social protection bemoan a lack of 'political will', and this is also true for Zambia. But the contested concept of 'political will' embodies an assumption that government (a) is a homogeneous and static body and (b) to a large extent, represents the will of most of the people. A useful contribution to the debate on political will would be to deconstruct 'the government' into its different actors and to undertake a more dynamic analysis of stakeholders.

Social protection in Zambia does have its supporters. MCDSS, once viewed as a passive actor in social protection (Barrientos et al. 2005) has evolved into an active, informed and more determined driver of change (Devereux and White 2010) that handles the previously baffling language of social protection with relative ease. Several MPs have recognised the political potential behind the SCT scheme and lobbied for the scheme to be extended to their constituencies. To this, one can add the evidence presented above on public opinion regarding government's responsibility for poverty reduction and (some) social assistance. Strategically, strengthening rather than criticising these stakeholders in the Zambian regime that promote social protection would be more constructive.

\subsection{Design and implementation - the devil in the detail?}

A further explanation offered for the failure (or slow momentum) of social protection interventions has been that the interventions are inappropriate.

\section{Best as enemy of the good?}

Devereux and White (2010) suggest that donors support technically superior but politically unpopular social protection interventions rather than supporting those programmes to which government is fully committed. While strengthening politically popular programmes seems a sensible avenue to take, we also have to critically ask ourselves why certain interventions - such as the Fertiliser Support Programme in Zambia - enjoy greater priority and support from the Ministry of Finance and to what extent they can be labelled as social protection. A recent World Bank evaluation (2010) demonstrates that the political attractiveness of this programme derives not from its pro-poor impact per se but from the political buy-in of better-off farmer recipients. How far such a programme can be fine-tuned to make it more pro-poor is hard to say if its unspoken aim is to reward those who can rally party support. 
Another critical question is whether existing social protection schemes can be expanded and improved. This requires a critical assessment of the extent to which existing interventions such as the in-kind support delivered through the Public Welfare Assistance Scheme (PWAS) of the MCDSS offer social protection, or employ mechanisms able to sustain a higher caseload, or enjoy political support. Given the challenges that PWAS faced in the past (Johnson and Do Rosario Advirta 2002), it was probably a reasonable choice to root the social cash transfer pilots in the old structure but to also test more efficient new modalities.

\section{Wrong target group and type of support?}

Would categorically targeted SCT rather than the poverty focus of the initial pilots have solicited more political support? The evidence from public attitude surveys does not support this, since we see greatest support across all samples for targeting the extremely poor, followed by people with disabilities, for the urban and rural sample as well as children among students. The political elites do not seem to be opposed to the target group of the poor and incapacitated either.

Might conditional support have been politically more popular? To get political buy-in in the short term, our attitude survey shows that a conditional cash transfer might increase political support. However, conditionality by itself will not do the trick: indirectly conditioned programmes such as the food security pack, school feeding or the in-kind PWAS support, have not received high levels of domestic financial allocations.

\section{Wrong process - never-ending piloting}

The recommendation by Devereux et al. (2010) that pilots be abandoned in favour of going national is hard to judge without a counterfactual. The experience of Lesotho suggests that going national fast can embed problems that are avoidable by testing and proceeding more gradually (Pelham 2007). Not going national can also be a precautionary measure: in what way would donor funding to a social protection system virtually disowned by power brokers in government be more promising - let alone possible - than the conservative approach of slowly increasing government's financial contributions?
What would count as an acceptable and realistic timeframe for a programme to go national? A programme that does not go national overnight is not necessarily a failure. However, when to call it a day is a difficult call to make in a country where policymaking is highly personalised, volatile and little influenced by the public vote. Sometimes having patience and perseverance are necessary for producing policy change.

\section{Conclusion}

Given the technical potential of social protection to address chronic poverty and vulnerability, observing slow progress in low-income countries as Zambia is frustrating. While also frustrating for Ministries of Social Affairs, cooperating donors and analysts, it is most serious for the poor and vulnerable themselves. Locating and strengthening the political support for issues low on the list of priorities for influential political players is complex, often gradual, and requires a readiness to seize the moment. This is particularly true in countries where only some policymaking or political incentives exist in official policy spaces. Here, citizens are still waiting to be able to hold their leaders accountable and conditions are absent for government to be viewed as entering into a social contract with its citizens.

Coming back to our initial questions, this investigation has highlighted that although many recommendations from previous studies were adopted and there was a strong commitment to engage in an evidence-based policy process, progress has been painfully slow. Simultaneously, this article has demonstrated the complexities of the political manoeuvring around social protection. Recommendations for strengthening political support for social protection are badly needed but must be attuned to the systemic features and political realities in Zambia, and must also prioritise the majority who are still trapped below the poverty line. Last but not least, more realistic timeframes and measurements should be employed to gauge success for complex political processes in lowincome countries, while unfavourable comparisons with rapid advances in countries like South Africa or Ethiopia should be avoided. 


\section{Notes}

* The authors would like to sincerely thank Franziska Gassmann for her valuable comments as well as the team at the Social Welfare Department of MCDSS for their input.

1 The previous constitution did not grant full socioeconomic rights. It even restricted basic

\section{References}

Barrientos, A.; Hickey, S.; Simutanyi, N. and Wood, D. (2005) Report of Study on Drivers of Change for a National Social Protection Scheme in Zambia, Lusaka: DFID Zambia

Devereux, S. and White, P. (2010) 'Social Protection in Africa: Evidence, Politics and Rights', Poverty and Public Policy 2.3: 53-77

Devereux, S.; Davies, M.; Sabates-Wheeler, R.; McCord, A.; Slater, R.; Freeland, N.; Ellis, N. and White, P. (2010) Social Protection in Africa: Where Next?, IDS, ODI, UEA-DEV, RHVP, www.ids.ac.uk/go/news/social-protection-inafrica-where-next (accessed 28 June 2011)

Habasonda, L.M. (2009) 'Political Economy of Cash Transfers in Zambia', report prepared for ODI, London: Overseas Development Institute

Hickey, S. (2007) Conceptualising the Politics of Social Protection in Africa, Working Paper 4, Manchester: Brooks World Poverty Institute

ILO (2008) Zambia Social Protection Expenditure and Performance Review and Social Budget, Geneva: International Labour Office

Johnson, D. and Do Rosario Advirta, M. (2002) Mid-term Review of the Project 'Public Welfare Assistance Scheme', Lusaka: Ministry of Community Development and Social Services

Levy, S. and Palale, P. (2007) Zambia: Governance, Political Economy and Development Strategy, Washington DC: World Bank

Lindström, C. (2008) 'The Politics of Institutionalising Social Protection in Zambia', MA dissertation, Brighton: IDS

McCord, A. (2009) Cash Transfers and Political Economy in Sub-Saharan Africa, Project Briefing 31, London: Overseas Development Institute (ODI)

Ministry of Finance and National Planning (2010) Yellow Book, Lusaka: Government of Zambia rights such as the right to education, claiming financial and administrative incapacity to do full justice to it.

2 For more information about the methodology and more findings, see Schüring (2010).

Niño-Zarazúa, M.; Barrientos, A.; Hulme, D. and Hickey, S. (2010) Social Protection in SubSaharan Africa: Will the Green Shoots Blossom?, Manchester: Brooks World Poverty Institute

Pelham, L. (2007) The Politics behind the Noncontributory Old Age Social Pensions in Lesotho, Namibia and South Africa, CPRG Working Paper 83, Manchester: Chronic Poverty Research Centre

Posner, D.N. and Simon, D.J. (2002) 'Economic Conditions and Incumbent Support in Africa's New Democracies: Evidence from Zambia', Comparative Political Studies 35: 313-38

Pritchett, L.H. (2002) It Pays to be Ignorant: A Simple Political Economy of Rigorous Program Evaluations, Harvard: Kennedy School of Government

RuralNet Associates Limited (2008) Assessing Administrative Capacity and Costs of Cash Transfer Schemes in Zambia. Implications for Rollout, Brasilia: International Poverty Centre and United Nations Children Fund

Schüring, E. (2010) Strings Attached or Loose Ends? The Role of Conditionality in Zambia's Social Cash Transfer Scheme, Kiel: Poverty Reduction, Equity, and Growth Network (PEGNet)

Vind-Andersen, Lena (2009) 'Zambia passes restrictive NGO law - NGO's protest', MS Zambia Newsletter August, www.ms.dk/ sw139035.asp (accessed 4 August 2011)

World Bank (2010) Zambia Impact Assessment of the Fertilizer Support Program. Analysis of Effectiveness and Efficiency, Report No. 54864-ZM, Washington DC: World Bank

Zambian Parliament (2010) www.parliament.gov.zm/index.php?option $=\mathrm{com}$ _content\&task = view\&id = 1 142\&Itemid = 86; www.parliament.gov.zm/index.php?option $=\mathrm{com}$ _content\&task =view\&id $=1336 \&$ Itemid $=86$ (both accessed 4 August 2011) 